\title{
Propuesta de autoevaluación de las organizaciones educativas
}

\author{
Proposal for self evaluation in educational organizations
}

\author{
Eithel Montiel Ortega, \\ Profesor Universidad de Costa Rica \\ eithel.montielortega@ucr.ac.cr \\ Dionel Méndez Salazar, \\ Administrador de la Educación \\ diomendez@costarricense.cr \\ Alexander López Campos \\ Administrador de la Educación \\ alexanderlc75@gmail.com
}

Recibido: 17 octubre 2010 Aceptado: 01 noviembre 2010 Corregido: 28 junio 2011

Resumen: El artículo trata sobre la autoevaluación de las organizaciones educativas, en la modalidad Dirección 1, en el Circuito 02-Pitahaya de la Dirección Regional de la provincia de Puntarenas, Costa Rica. En esas instituciones se ejecutó una adaptación al contexto de la educación costarricense de los modelos internacionales para la certificación de la calidad educativa, como el de la Organización Internacional para la Estandarización (ISO) y el de la Fundación Europea para la Gestión de Calidad (EFQM). Para ello, se tomó como muestra al personal docente y directivo de las instituciones en estudio, así como a las personas integrantes de las juntas de educación, patronatos escolares y gobiernos estudiantiles. En el proceso, se adaptaron los instrumentos de los modelos (ISO) y (EFQM) a un lenguaje cotidiano, para que esas poblaciones identificaran las preguntas necesarias para la autoevaluación, de acuerdo con el contexto de cada organización educativa bajo investigación.

Finalmente, se presenta una propuesta de autoevaluación contextualizada a las Escuelas Dirección 1, que dé a estos procesos evaluativos un sentido práctico, en procura de mejorar la calidad de la educación.

Palabras Clave: Organizaciones educativas, evaluación, autoevaluación, calidad educativa, eficiencia, eficacia, Organización Internacional para la Estandarización (ISO) y Fundación Europea para la Gestión de Calidad (EFQM)

Abstract: This article focuses on a synthesis of self-education organizations in an address mode circuit 02-Pitahaya Regional Directorate of the province of Puntarenas, Costa Rica, where he ran an adaptation of international standards for certification educational quality, as the International Organization for Standardization (ISO) and European Foundation for Quality Management (EFQM) to the context of self-evaluation of Costa Rican education. For this purpose a sample was taken to the teachers, principals, school boards, school boards and student governments. Later, they adapted the tools of the models (ISO) and (EFQM) in everyday language so that these people 
discriminate the items considered necessary for a self-assessment with the context of each educational organization under study.

Finally, we present a proposal for self-contextualized to the Schools Division One, which enables them practical meaning to the evaluation processes, seeking to improve the quality of education.

Keywords: Educational Organizations, Evaluation, Self Assessment, Educational Quality, Efficiency, Effectiveness, ISO (International Organization for Standardization) and EFQM (European Foundation for Quality Management)

\section{Introducción}

La sociedad moderna se caracteriza por los cambios y transformaciones de la época, donde las personas y las organizaciones se desenvuelven en un ambiente de competitividad, en el cual deben doblar esfuerzos para ser más productivas. La globalización se caracteriza por entornos de sinergia, que se da por medio de la generación e intercambio de bienes y servicios, para producir ingresos en las distintas dimensiones que incursiona el ser humano.

La Era de la Información, comprendida aproximadamente desde la década de 1990 hasta hoy, provocó cambios inesperados que, según Drucker (1995) hace énfasis en una transformación mundial, al afirmar que "la tecnología produjo desarrollos por completo imprevistos y transformó el mundo en una aldea global. La información logró recorrer el planeta en milésimas de segundo. La tecnología de la información provocó el surgimiento de la globalización de la economía" (Chiavenato, 2007 , p. 9-8). Ante este panorama, la administración de la educación debe servir de plataforma para que quienes administran la educación asuman los cambios y las transformaciones, que permitan un constante crecimiento del conocimiento, pues este se convierte en la clave del progreso y el poder para mejorar las acciones del currículo en todas sus dimensiones; sin embargo, esta sistematización debe acompañarse de procesos de evaluación y autoevaluación, para determinar el grado de avance y mejoramiento del proceso educativo.

La autoevaluación de organizaciones educativas es un campo de estudio importante en la actualidad. Según Tiana (1996), posee relevancia tanto en el aspecto político como en la administración educativa. Estos dos elementos se relacionan con lo que se podría llamar la presión del cambio que experimentan los sistemas educativos actuales, la dinámica con que se generan los cambios, las respuestas que deben dar las organizaciones a las nuevas demandas y la consecución de procesos de innovación, se convierten en aspectos relevantes de las políticas educativas, donde las organizaciones asuman características de flexibilidad y den respuestas inmediatas a las diferentes demandas de la sociedad.

El proceso de autoevaluación implica la consideración de una serie de aspectos de índole integral, como la dimensión pedagógica, social, cultural y su impacto organizacional, involucrando a toda la comunidad educativa, desde un punto de vista reflexivo, analítico, crítico e innovador, que facilite un encuentro de todas las dimensiones del centro educativo, conducentes al cambio para la mejora de la realidad 
institucional. El tema del proyecto de investigación que se describe a continuación tuvo como objeto de estudio la autoevaluación de las organizaciones educativas, de instituciones del sistema educativo público costarricense, en la modalidad Dirección 01, en el Circuito 02, Pitahaya, de la Dirección Regional de Puntarenas. Los objetivos del estudio fueron los siguientes:

\section{Generales:}

- Analizar, participativamente, los modelos de la Organización Internacional para la Estandarización (ISO) y de la Fundación Europea para la Gestión de Calidad (EFQM) en el contexto de la evaluación de la educación costarricense.

- Desarrollar, a partir del análisis de los modelos de la ISO y EFQM, un instrumento de autoevaluación aplicable a las organizaciones educativas modalidad dirección uno en el Circuito 02, Pitahaya, de la Dirección Regional de Puntarenas.

\section{Específicos:}

- Determinar los indicadores de autoevaluación según el modelo de Organización Internacional para la Estandarización (ISO) y Fundación Europea para la Gestión de Calidad (EFQM) que consideran más significativos los padres, madres, estudiantes, docentes, directores y directoras inmersos en el contexto organizacional de las escuelas modalidad uno del Circuito 02, Pitahaya, de la Dirección Regional de Puntarenas.

- Proponer un modelo de autoevaluación de las organizaciones educativas de modalidad dirección uno en el Circuito 02, Pitahaya, de la Dirección Regional de Puntarenas.

\section{Hallazgos de la investigación sobre la evaluación y la autoevaluación institucional}

Para abordar el tema de evaluación y autoevaluación se consultaron diferentes estudios. Tiana (1996) hizo un breve recorrido por la evolución de este fenómeno y resalta que desde finales de la década de 1980 y durante la década de 1990, se pusieron en marcha mecanismos institucionales, centros u organismos de evaluación de los sistemas educativos en países como Francia, Suecia, Noruega, España, Argentina y Chile. Asimismo, indica que se han desarrollado planes sistemáticos de autoevaluación en el Reino Unido, Holanda, Francia, Argentina, Chile, República 
Dominicana y México, basados en los indicadores evaluativos de la educación a nivel nacional de países como Estados Unidos, Francia, Dinamarca y Suiza.

También, se realizaron numerosos estudios cuantitativos y aportes a la autoevaluación de organizaciones educativas, entre los cuales destaca el trabajo de evaluación de centros educativos de secundaria en el País Vasco, a cargo de Lukas (2004), donde se presenta el modelo de evaluación de centros escolares de educación secundaria que se aplica en la Comunidad Autónoma Vasca (España), que tenía como propósito ofrecer información relevante para instaurar procesos de cambio y mejora institucional en cada una de las escuelas participantes. Sin embargo, este análisis no pretendía controlar, seleccionar ni ordenar los centros educativos, sino detectar las virtudes y limitaciones de cada institución para que plantearan proyectos de mejora y cambio.

Un estudio de Miguel Andrés (2005) contextualiza el sistema de la Organización Internacional para la Estandarización (ISO) para la gestión por procesos y los criterios de autoevaluación de la Fundación Europea para la Gestión de Calidad (EFQM), en un contexto educativo con finalidades diferenciadas con el mundo de la empresa. Esta propuesta utiliza las ventajas de la ISO y del modelo EFQM, para concretar un sistema de recogida de información, mediante indicadores orientados a la toma de decisiones para la mejora de la calidad en las organizaciones educativas. Se considera que este es un instrumento de anclaje en la realidad de los modelos de organización colaborativos, que se distancia de los posibles peligros del discurso seductor de la calidad.

Después de una revisión bibliográfica de nivel internacional sobre el tema de evaluación y autoevaluación de centros educativos fue preciso revisar investigaciones en el país, para establecer un contacto directo con el tema en el contexto nacional. Al respecto, fue interesante la investigación de enfoque cualitativo de Zúñiga (2003), sobre la autoevaluación de una escuela Dirección 02 (El Llano), ubicada en el distrito de San Antonio del cantón de Alajuelita, de la provincia de San José, en la que se concluyó que la autoevaluación permite identificar problemas que afectan el desarrollo óptimo de los procesos de enseñanza y aprendizaje. Con base en los hallazgos de ese estudio se inició la creación de una cultura de autoevaluación dentro del seno institucional, con base en la cual se determinan áreas débiles y fuertes, en aras del mejoramiento de la calidad de los procesos.

Ese nuevo enfoque irrumpió en los indicadores que tradicionalmente han utilizado el MEP y la UNESCO para evaluar la calidad de la educación, entre los que se encuentran las tasas de repitencia, rendimiento académico, idoneidad profesional, programas de estudio, capacitación docente e infraestructura. Con ello, se simplificó y estandarizó la realidad del fenómeno educativo, debido al manejo acrítico que imperaba y que llena de limitaciones e inconsistencias el estudio y la evaluación de la calidad del sistema educativo costarricense. 


\section{Referencial teórico de la investigación}

La evaluación de las organizaciones educativas se ha planteado como un juicio de valor, que busca la mejora constante de los estándares de calidad de la educación. Según Acuña (1989), citado por Romero (2001, p. 669) "el proceso evaluativo aplicado a una institución educativa nos permite obtener un juicio valorativo, las cualidades y los méritos"; de esta forma, la evaluación mostrará información que permite determinar un carácter diagnóstico y procesal, en la medida que se evidencian las condiciones y recursos con los que cuenta la organización y, a partir de esa disyuntiva, plantear un desarrollo de acuerdo con los recursos disponibles.

Cronbach (1963), citado por Santos Guerra (2000, p. 27) "distingue tres grandes áreas sobre las que la evaluación toma decisiones: el material de instrucción, los individuos y la regulación administrativa". El proceso de evaluación comprende las condiciones en que se desarrollan las acciones, los medios disponibles, la normativa vigente, así como la política educativa que se implementa en los programas oficiales. Por esta razón, se enfatiza la evaluación como un proceso integral, que diagnostica diferentes contextos. Además, se le acredita un papel preponderante en la toma de decisiones, al dictaminar que se basa en el acopio y uso de información para tomar orientar las decisiones sobre un programa educativo.

Nájera (1973), citado por Gento Palacios (2000, p. 296), al referirse a la evaluación comenta: "El estudio del valor corresponde a una rama de la filosofía que es la axiología y los conceptos cambian de acuerdo con el sentido filosófico que la persona aprovecha"; de tal modo, se determina el concepto dinámico que tiene la evaluación, es decir, de acuerdo con el requerimiento que le asigne el evaluador, así será su función.

La evaluación es un proceso sistemático complejo, que muestra muchas configuraciones. Al respecto, Gairín (2002) considera que "la evaluación es un proceso reflexivo, sistemático y riguroso de indagación para la toma de decisiones sobre la realidad, que atiende a su contexto, abarca tanto lo explícito como lo implícito y efectos secundarios y se rige por principios de utilidad, participación y ética" (p. 118). Esto indicaría que se visualiza la evaluación como un proceso de investigación que integra a todos los actores de la organización educativa, de manera sistemática y democrática. Además, toma en cuenta los factores internos y externos que condicionan el desarrollo de los procesos educativos, que son valiosos en la toma de decisiones para la búsqueda de la calidad de la educación.

La evaluación constituye una parte importante del proceso de enseñanza y aprendizaje, así como del centro educativo y tiene un papel protagónico en el desarrollo de las actividades que le son propias. La evaluación no puede verse como algo decorativo que se realiza al final de los procesos, y después no se hace nada con los resultados obtenidos; por el contrario, debe estar compenetrada con todas las unidades de la organización, puesto que su función debe ser de cambio y mejora constante. 


\section{La autoevaluación}

La autoevaluación es un proceso que se encuentra íntimamente relacionado con la evaluación educativa. La principal diferencia y ventaja de la primera es que se lleva a cabo desde lo interno de la organización educativa. Algunos autores, como Luján y Puente (1996), las clasifican como evaluación externa y evaluación interna (la autoevaluación), pues en ella participan la comunidad educativa y el profesorado, originando lazos inquebrantables entre los diferentes actores en la búsqueda de procesos educativos de calidad, ya que permite el conocimiento de situaciones que afectan el proceso curricular, que no se vislumbrarían si el proceso evaluativo se efectuara de forma externa.

En esta tendencia, De Miguel, Madrid, Noriega y Rodríguez (1994), citados por García (2001) resaltan la autoevaluación como la estrategia más oportuna para conseguir el mejoramiento de los centros educativos, mediante la autorrevisión o autoanálisis, como proceso evaluador por parte de los mismos sujetos que componen la comunidad educativa. Desde esta perspectiva, la autoevaluación se concibe como un sumario continuo y escalonado, que valida las estrategias de análisis de autogestión, al revisar periódicamente las metodologías empleadas en la organización, para impregnar un paradigma evaluador que consentirá un replanteamiento de la misión y visión institucional, permitiendo ejecutar valoraciones que emitan juicios que guíen la construcción y reconstrucción permanentes de los diferentes procesos evaluativos que se desarrollan, para fortalecer y alimentar el progreso de perfeccionamiento de las organizaciones.

Por sus características, la autoevaluación dota a la institución educativa de un esquema de trabajo para su organización y funcionamiento; al mismo tiempo, beneficia el establecimiento de una cultura de reflexión y análisis en los centros educativos y el equipo docente que lo constituye. Igualmente, promueve el trabajo colaborativo del profesorado, al superar las tendencias individuales y favorecer la creación de una idiosincrasia institucional. Por ello, sus resultados se utilizan en forma inmediata, por quienes se encuentran inmersos en el proceso de enseñanza y esto motiva al personal directivo y docente, y permite engrandecer la imagen y calidad del centro escolar.

\section{Calidad de Educación}

El concepto de calidad ha evolucionado con el paso del tiempo; por ello, paulatinamente, se han dado transiciones en cuanto a su connotación como resultado de la evolución del principio del potencial humano como mecanismo de mejora constante dentro de las organizaciones.

Al hacer referencia al concepto de calidad de la educación aparecen distintos parámetros epistemológicos, comparaciones e ideales que serían imposibles de alcanzar en cualquier sistema educativo, región educativa u organización escolar; sin embargo, la calidad depende del contexto y las condiciones propias de cada centro educativo, así como de la disposición de recursos, económicos, físicos, materiales y humanos disponibles. 
Para efectos de la investigación descrita, fue conveniente mantener un enfoque de calidad como "perfeccionamiento o mérito", pues esto implica una búsqueda constante del mejoramiento, que se logra por medio de la evaluación permanente de los procesos y resultados, con la participación de los actores educativos en búsqueda de la satisfacción de las necesidades educativas del alumnado. Como indican Garbanzo y Orozco (2008), "una educación de calidad es la que logra que el estudiantado aprenda lo que debe aprender en el tiempo estimado y de la mejor manera, haciendo uso racional de los recursos de que dispone el sistema para la concreción del proyecto educativo" (p. 10). En consecuencia, quienes administran la educación deben dar cuenta del producto que ofrece la organización educativa que tienen bajo su responsabilidad. Ante esta situación, el Administrador o la Administradora de la Educación encaminarán sus acciones a potenciar a sus colaboradores, de manera que, cooperativamente, se asuma la responsabilidad social de los procesos evaluativos que el centro escolar realice para la mejora continua.

\section{Eficiencia y eficacia en educación}

Toda organización relacionada la prestación de servicios, sea lucrativa o no, procura ser eficiente y eficaz, puesto que ello determina la excelencia de la gestión y el logro o fracaso ante las metas previstas. Al respecto, Sander (1990) define la eficacia como la capacidad de la organización administrativa de alcanzar las metas propuestas, posibilitando el logro de los objetivos educativos que se traducen en la obtención de resultados; asimismo, plantea la eficiencia como el logro del éxito, con la menor cantidad de recursos, energía y tiempo.

Chiavenato (2007) propone que la eficacia es la capacidad de la organización de lograr resultados, satisfaciendo una necesidad de la sociedad mediante bienes o servicios; sin embargo, la eficiencia conlleva una medición de los recursos que se emplean, para obtener un producto terminado; en otras palabras, es la razón entre el esfuerzo y el resultado, entre el gasto y el ingreso, entre el costo y el beneficio resultante. Desde esa perspectiva, la eficacia en Educación se definiría como la contundencia de las estrategias utilizadas dentro del marco de los propósitos, alcances y logros manifiestos en las diferentes dimensiones del currículo. Además, este proceso se evidenciaría y expresaría en el aprendizaje de los discentes dentro de un contexto educativo particular.

\section{Certificaciones Internacionales de la Calidad de la Gestión Administrativa}

La evaluación es un factor determinante de la calidad; asimismo, la autoevaluación es necesaria para contextualizar la calidad educativa; no obstante, para que exista una verdadera relación entre calidad y autoevaluación de la educación se requieren mediaciones sistemáticas que garanticen su efectiva implementación. Por esta razón, en el ámbito empresarial se usan certificaciones internacionales, como la norma ISO (Organización Internacional para la Estandarización) y el EFQM (Fundación Europea para la Gestión de la Calidad) que garantizan el proceso de 
autoevaluación de la calidad, que varios países como España y México, por citar algunos, adoptaron en el ámbito educativo.

La ISO es una agencia internacional especializada en normalización, cuyo objetivo es ayudar al desarrollo de estándares en la Era de la Globalización, para promover el intercambio de mercancías y la prestación de servicios entre las naciones, logrando un entendimiento en los dominios científicos, intelectuales, técnicos, económicos y, recientemente, en el ámbito educativo, con especial atención a la experiencia, mexicana, como plantea Yzaguirre (2005), puesto que son muchas las oficinas e instituciones educativas que han obtenido la certificación ISO 9000:2000, en razón de que el propio Sistema de Educación Pública le ha dado un gran impulso.

Para que una organización funcione de manera eficaz se deben identificar y administrar numerosas actividades, en especial, sin se utilizan recursos con el fin de propiciar que los elementos de entrada se conviertan en resultados; esto es, considerando a la organización como un proceso.

Normalmente, el resultado de un proceso establece los elementos de entrada de cada uno de sus pasos o fases. Por ello, son dinámicos, flexibles y facilitan el establecimiento de nuevos criterios conforme se consiguen los objetivos y metas trazadas, permitiendo hacer los ajustes necesarios sobre la marcha para mejorar y perfeccionar los resultados de la organización. El proceso y las fases en el modelo ISO 9000:2000, se representan en el diagrama 1.

Diagrama 1

Modelo ISO 9000:2000

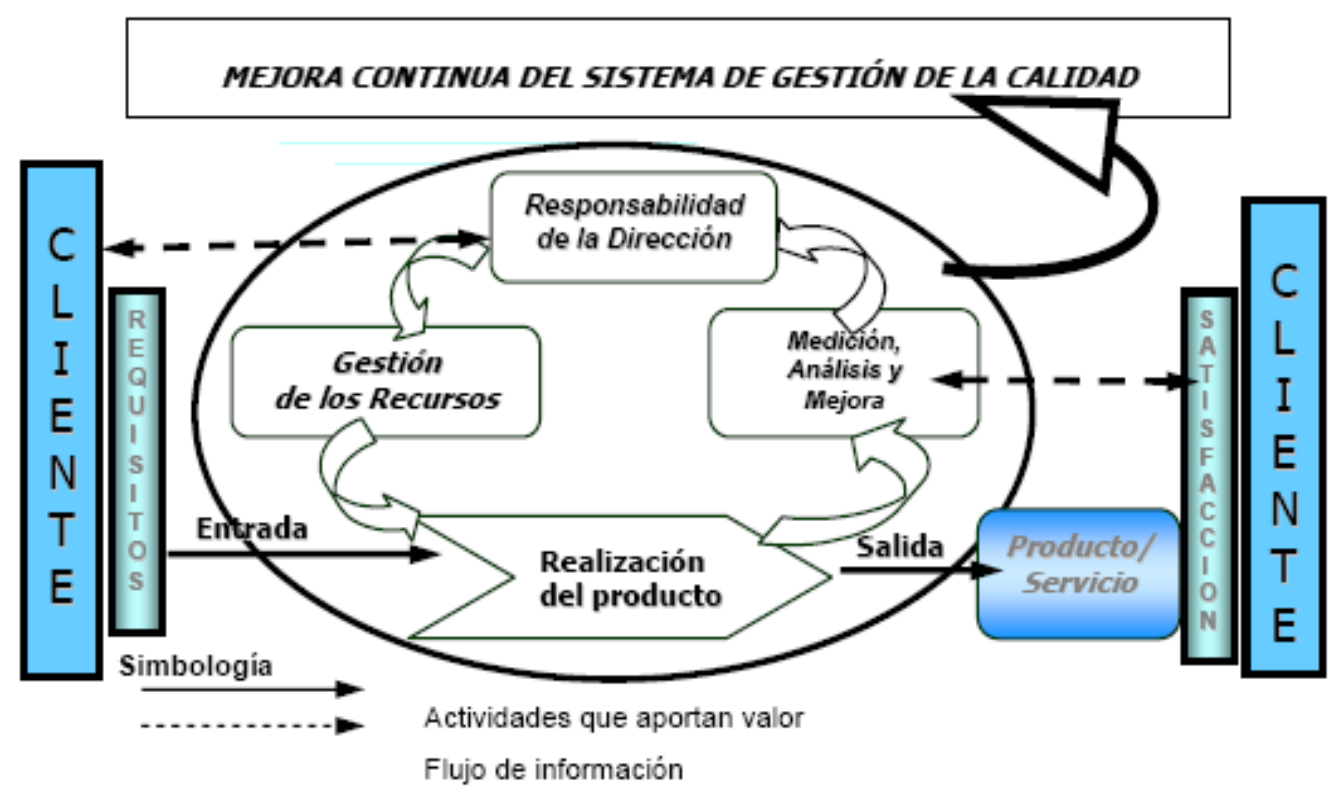

Fuente: Tomado de Villalta (2007, p.4). 
Los principios operativos de la norma de estandarización ISO, se basan en el modelo que se presenta en el cuadro 1.

\section{Cuadro 1}

Principios de un Sistema de Calidad

1. Responsabilidad de la Gestión:

- Política de Calidad.

- Objetivos de Calidad.

- Responsabilidad y Autoridad de Calidad.

- Revisión de la Gestión.

2. Estructura del sistema de Calidad:

- Espiral de Calidad del Servicio.

- Documentación y Registro de Calidad.

- Revisiones de Calidad Interna.

3. Personal y Recursos Materiales:

- Personal:

$\checkmark$ Formación y desarrollo.

$\checkmark$ Comunicación

- Recursos materiales.

4. Interacción con los clientes

Fuente: Criterios de evaluación de Calidad total en Empresas de Servicios: ámbito de operaciones a realizar (Modelo ISO, 9004-2) (Gento, 1995, p. 39).

Con base en el modelo y retomando los aportes de Yzaguirre (2005) y Rosario (2006), poner en ejecución el concepto de calidad consiste en una disciplina y, por lo tanto, requiere constancia en las experiencias y acciones del personal que conforma la organización; requiere sensatez en la descripción de los caminos que se siguen, sin dejar de lado la documentación indispensable para publicar que se tiene calidad, de acuerdo con la norma en mención, tales como manuales de calidad, política y objetivos de calidad, manual de procesos, procedimientos, instructivos, registros, formatos y otros. Este aspecto se encuentra íntimamente relacionado con el compromiso y los valores de los colaboradores y la influencia ejercida por el liderazgo de la persona a cargo de la Administración y de la motivación para alcanzar los mejores estándares en los resultados obtenidos; esto, en cuanto a la visión y misión de la organización.

También, es importante analizar el modelo de calidad EFQM, cuyo propósito es la mejora continua y, para ello, se realizan mediciones bajo la asignación de puntos. Adquirir el sello de esta organización asegura y comprueba que la instancia evaluada 
ha mejorado en su fase operativa, al superar el nivel anterior y progresar hacia el siguiente nivel de excelencia. Este modelo lo constituyen nueve elementos o criterios, ordenados en dos grandes bloques, como se evidencia en el diagrama 2.

\section{Diagrama 2 \\ Modelo EFQM}

Modelo europeo de gestión de la calidad

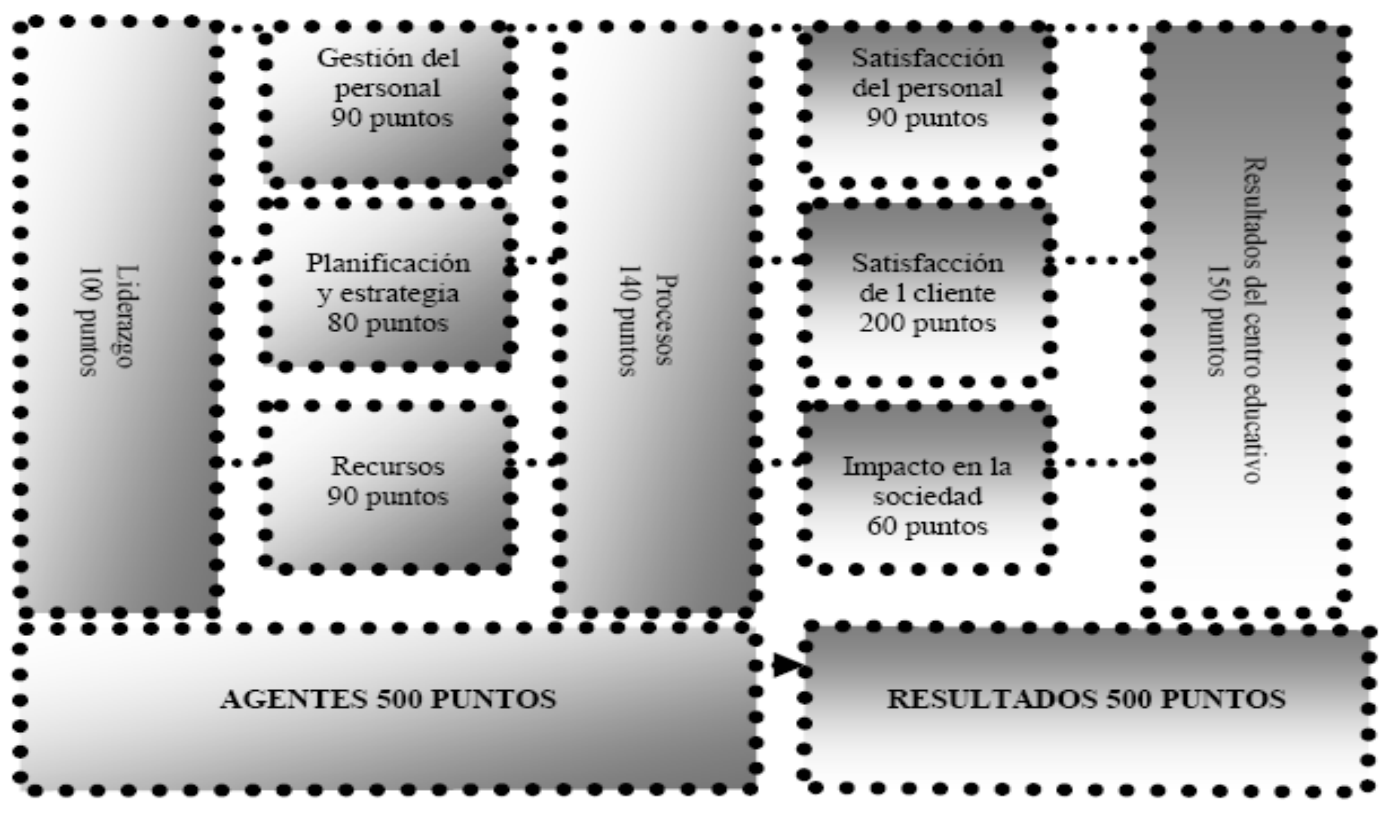

Fuente: Modelo de la Fundación Europea para la Gestión de la Calidad (García, 2001, p. 27).

El primer bloque de este modelo está formado por los elementos que la organización posee para alcanzar sus metas. El segundo conjunto lo estructuran los resultados que alcanza la organización. No obstante, la equivalencia existente en los agentes, se considera en ambos modelos (ISO y EFQM), y la importancia que el modelo EFQM otorga a los resultados hace la diferencia y la ventaja principal frente al modelo ISO.

El modelo EFQM tiene cinco indicadores: liderazgo, política y estrategia, personas, recursos y alianzas, y procesos. Asimismo, modelo hace referencia a dos perspectivas: la primera, enfocada a lo realizado por el centro; la segunda, en función de lo que obtiene la organización, visualizándose así la satisfacción con el centro, el personal, el impacto en la sociedad y los resultados del centro; con ello, se logra una interrelación en cada una de las dimensiones de la organización.

Para el Ministerio de Educación y Cultura (MEC) de España, (1997), citado por García (2001, p. 27), "la satisfacción de los usuarios del servicio público de la 
educación, de los profesores y del personal no docente, y el impacto en la sociedad se consigue mediante un liderazgo que impulse la planificación y la estrategia del centro educativo, la gestión de su personal, de sus recursos y sus procesos hacia la consecución de la mejora permanente de sus resultados". Por sus ventajas, este modelo de autoevaluación y mejora constante se ha implementado en diversos centros educativos de ese país, para lo que el MEC, en coordinación con el club gestor de calidad, hizo adaptaciones para los diferentes contextos educativos y regiones.

\section{Metodología de la investigación}

En la metodología del estudio descrito, se solucionó el problema que originaba la creación de un modelo de autoevaluación, pues subsanaba una carencia del Ministerio de Educación Pública (MEP) de Costa Rica. Por la naturaleza del problema en estudio, se utilizó una metodología cuantitativa que, según Bisquerra (2000, p. 63), parte de la aplicación de un cuestionario o "pruebas objetivas y otros instrumentos de medida sistemática; es característica relevante la aplicación de la estadística en el análisis de datos". La aplicación de los instrumentos permitió la recopilación de la información y la sistematización de los datos.

Al ser una investigación de tipo no experimental, se utilizaron objetivos en lugar de hipótesis para elaborar el instrumento, que permitieron diseñar una propuesta de evaluación de las organizaciones educativas en la modalidad Dirección 01, en el Circuito 02 Pitahaya, de la Dirección Regional de Puntarenas.

\subsection{Población en estudio}

La población en estudio fueron diez docentes que laboran en un código específico de cada institución objeto de estudio. No se encuestó al profesorado de asignaturas especiales que se desplazan de otras zonas a completar lecciones a estas instituciones y laboran solamente un día a la semana en el centro educativo; con ello, se evitó el sesgo de información derivado de un bajo sentido de pertinencia institucional y escasa lectura del entorno social.

Se incluyó a los cinco directores o directoras de cada escuela, para obtener su criterio sobre la autoevaluación institucional. También, se incluyó a sesenta padres y madres de familia, miembros del Patronato Escolar y de la Junta de Educación de las escuelas Dirección 01, para conocer la percepción de los usuarios que apoyan el proceso administrativo de las escuelas en estudio. Se encuestó a los 431 estudiantes, porque son los usuarios directos de los centros educativos y su razón de existir, por lo que su opinión fue de suma importancia para este trabajo. El resultado fue una población global de 511 sujetos, quienes aportaron información relevante del estudio.

De la población total, se investigó una muestra estratificada y Hernández, Fernández y Baptista (2007, p. 247), la definen como el "Subgrupo en que la población se divide en segmentos y se selecciona una muestra para cada segmento". En concordancia con lo anterior, los sujetos de investigación se agruparon en subgrupos de estudiantes, padres y madres de familia que integraban el Patronato 
Escolar y la Junta de Educación, los docentes, directores y directoras, miembros de las escuelas Dirección 01.

El estrato de directores y directoras representó un 1\% de la población total; al ser tan bajo, se aplicó el instrumento a toda la población de este estrato. Igual situación sucedió con el estrato de docentes que representó el $2 \%$ del total de la muestra, por lo que se consideró en el estudio a los diez educadores y educadoras. Concerniente al grupo de padres, madres y encargados, que mantuvieron un porcentaje de $12 \%$ del total de la muestra. Con respecto a este estrato, se tomó el $50 \%$, definiendo la participación necesaria de los presidentes de cada órgano de apoyo, Junta de Educación y Patronato Escolar, además de dos miembros más de cada órgano escogidos al azar por institución, lo que alcanzó un total de 30 sujetos de investigación. Referente a los estudiantes, se trabajó con la totalidad de integrantes de los gobiernos estudiantiles de cada institución, que totalizaron 30 estudiantes, distribuidos en cada nivel de los ciclos de la Educación General Básica. De esta manera, se obtuvo como resultado una muestra total de 75 sujetos de investigación distribuidos en el siguiente cuadro.

\section{Cuadro 2}

Distribución de población y muestra en porcentajes y absolutos

\begin{tabular}{l|c|c|c|c}
\multirow{2}{*}{ Estrato } & \multicolumn{2}{|c|}{ Población } & \multicolumn{2}{c}{ Muestra } \\
\cline { 2 - 5 } & Porcentajes & $\begin{array}{c}\text { Números } \\
\text { absolutos }\end{array}$ & $\begin{array}{c}\text { Porcentajes con } \\
\text { respecto a la } \\
\text { población del estrato }\end{array}$ & $\begin{array}{c}\text { Números } \\
\text { absolutos }\end{array}$ \\
\hline Docentes & 2 & 10 & 100 & 10 \\
\hline Directores & 1 & 5 & 100 & 5 \\
\hline Estudiantes & 85 & 431 & 7 & 30 \\
\hline Padres & 12 & 60 & 50 & 30 \\
\hline TOTAL & $\mathbf{1 0 0}$ & $\mathbf{5 1 1}$ & $\mathbf{N}$. A. & $\mathbf{7 5}$ \\
\hline
\end{tabular}

Fuente: Población objeto de estudio, Circuito 02 Pitahaya de la Dirección Regional de educación de Puntarenas. Noviembre, 2008.

*(No aplica)

Al tener definido cada subgrupo, se otorgó equitativamente el número de sujetos que correspondió a la aplicación del cuestionario por institución educativa. Para el total de docentes, directores y directoras, se tomó el 100\% de la población de cada estrato, 30 educadores y educadoras y 5 directores o directoras. Del estrato de padres y madres de familia se trabajó con 30 integrantes del patronato escolar y de la junta de educación y se designó a seis por cada institución, de los cuales los presidentes de cada órgano fueron un pilar fundamental, además de dos miembros adicionales que integraran el patronato y dos de la junta de educación; para este caso, se utilizó un muestreo aleatorio simple, el cual consistió en ubicar en dos tómbolas diferentes los nombres de los padres y madres que integran el patronato escolar y una 
para los integrantes de la junta de educación, de las cuales se extrajo el nombre de dos miembros por cada una, con la obtención de las personas que aportaron parte de la información relevante para este estudio.

Para seleccionar el subgrupo de estudiantes, se utilizó un muestreo no probabilístico, denominado por Buendía, Colás y Hernández (1998) como "muestreo deliberado", en el cual de la cantidad de niños y niñas, se asignaron seis cupos por escuela; para ello, se tomó el gobierno estudiantil como muestra representativa de cada institución, puesto que este órgano es elegido democráticamente por la población estudiantil de cada centro; además, en su estructura se representaron los seis niveles de la educación general básica, un niño o una niña por nivel.

\subsection{Fuentes de información primaria}

Las fuentes primarias que se utilizaron corresponden a la información brindada por los sujetos objeto de estudio, por medio de una escala Likert, la cual consiste, según Hernández, Fernández y Baptista (2007, p. 341), en un "conjunto de ítems que se presentan en forma de afirmaciones para medir la reacción del sujeto en tres, cinco o siete categorías". En este estudio, se utilizaron cuatro instrumentos de acopio de información mediante una escala con cinco categorías de valoración: indispensable, muy importante, importante, poco importante y nada importante.

Además, se contó con fuentes secundarias respaldadas por investigaciones previas sobre la temática en estudios publicados en revistas, libros y consultas de Internet entre otros.

\subsection{Técnicas de recolección de la información}

Para construir los instrumentos de recopilación de información, se realizó la categorización del primer objetivo específico, al cual se le definió como la categoría de análisis de cada uno de los criterios que utilizan la ISO y EFQM, delimitándolas conceptualmente de acuerdo con diferentes autores, donde se desdoblaron y fusionaron las semejanzas de ambos modelos, que, a su vez, se definieron operacionalmente y se renombraron con un vocabulario contextualizado y propio de la idiosincrasia de la población objeto de estudio. Finalmente, se hizo la redacción final de los criterios de autoevaluación que se propondrían en cada uno de los cuatro instrumentos, como sigue:

a) Para el indicador "usuarios", se concibe operacionalmente, como la eficiencia y eficacia en la prestación del servicio educativo de todo aquel que se beneficia directamente de las actividades del centro. Son usuarios directos el alumno y su familia.

b) El indicador "liderazgo", se entiende como la influencia del director y de los responsables del centro educativo sobre la mejora continua de la institución. 
c) Los indicadores referidos a "órganos de apoyo", se entienden como la utilización eficiente de los recursos en el centro educativo, en función de la planificación y de las estrategias establecidas por la organización para ese efecto.

d) Por "procesos", se entiende el cúmulo de actividades que se desarrollan para lograr la formación del alumno y la prestación de los servicios que ofrece el centro educativo.

e) La noción de "proyección social" comprende la integración y alineación de los procesos que alcanzarán los resultados deseados y el logro de los objetivos previstos en el centro educativo, que impactan la organización.

f) Por "competitividad", se entienden los resultados del centro educativo que se reflejan en los logros en el área educativa, la gestión y las acciones que contribuyan al éxito de la organización.

g) Por "planificación", se entiende la forma en que se realizan los planes y proyectos, en respuesta a las demandas de la sociedad y al mejoramiento continuo del centro.

h) El "personal" es el recurso humano, interno y externo, y la forma en cómo es guiado para lograr eficiencia y eficacia, por medio del trabajo en equipo para la consecución de los objetivos institucionales.

\subsection{Sistematización y análisis de la información}

La recopilación y sistematización de la información, se hizo mediante la construcción de cuatro cuestionarios tipo likert, dispuestos para cada uno de los conglomerados definidos en la población en estudio: directores, directoras, docentes, padres, madres y estudiantes, donde se analizaron, de acuerdo con su percepción, aquellos indicadores que se ajustaron a sus necesidades e intereses inmediatos, y seleccionaron los indicadores autoevaluativos asociados al ideal pedagógico y organizacional por cumplir en la región educativa del Circuito 02 de Pitahaya, de la Dirección Regional de Puntarenas.

Debido al tipo de muestreo empleado, la información obtenida fue la base para fijar los indicadores de autoevaluación que debe contener la propuesta de autoevaluación institucional a desarrollar. Para ello, se codificó cada respuesta en una escala del 1 al 5, se tabularon las respuestas de cada conglomerado en una hoja de cálculo, y se obtuvo el promedio de cada indicador. Para el diseño de la propuesta de autoevaluación se seleccionaron los que igualaron o superaron la media total obtenida en cada instrumento.

La información se sistematizó en cuadros con estadísticas descriptivas. En algunos casos se elaboraron gráficos, donde se presentaron los ocho indicadores que 
resultaron de la fusión de los criterios de la ISO y EFQM descritos anteriormente: planificación, competitividad, usuarios, órganos de apoyo, liderazgo, procesos, personal y proyección social.

Para el análisis de la información, se tomaron en cuenta los criterios, desde la óptica de los gestores de la administración educativa, que facilitan la construcción de una propuesta de autoevaluación amparada al conocimiento y vivencias sobre el contexto en que se desenvuelven laboralmente, con la finalidad de establecer lineamientos, ajustes y aportaciones necesarias para la búsqueda constante de la mejora continua de todos los procesos que suceden en las organizaciones educativas.

Directores y directoras de la administración de la educación deben ser conscientes de que una de sus principales funciones reside en elaborar proyectos educativos de centro que respondan a las inquietudes inmediatas de la comunidad, enlazando la sinergia que sucede en la aldea global. Para ello, una de las herramientas que se puede utilizar para diagnosticar la eficiencia y el alcance de dichos programas es la autoevaluación. En este trabajo de investigación se tomaron en cuenta de forma participativa y, a la vez, individual, desde la óptica de los gestores de la administración educativa, una serie de criterios que facilitan la construcción de una propuesta de autoevaluación amparada en el conocimiento y vivencias sobre el contexto en que se desenvuelven laboralmente. La información que se presenta en el siguiente cuadro, representa una contextualización de los indicadores de cada una de las áreas presentadas en el instrumento aplicado a directores y directoras de las instituciones objeto de estudio.

\section{Cuadro 3}

Síntesis del promedio según indicadores seleccionados y excluidos por los Directores y Directoras, Circuito 02, Dirección Regional de Puntarenas

\begin{tabular}{|c|c|c|c|c|c|}
\hline \multirow{2}{*}{ Áreas } & \multirow{2}{*}{$\begin{array}{c}\text { Total de } \\
\text { Indicadores del } \\
\text { Instrumento }\end{array}$} & \multicolumn{2}{|c|}{ Indicadores Incluidos } & \multicolumn{2}{|c|}{ Indicadores Excluidos } \\
\hline & & Absolutos & Porcentaje & Absolutos & Porcentaje \\
\hline Planificación & 17 & 10 & 59 & 7 & 41 \\
\hline Competitividad & 12 & 3 & 25 & 9 & 75 \\
\hline Usuarios & 18 & 11 & 61 & 7 & 39 \\
\hline Órganos de Apoyo & 11 & 2 & 18 & 9 & 82 \\
\hline Liderazgo & 9 & 6 & 67 & 3 & 33 \\
\hline Procesos & 12 & 3 & 25 & 9 & 75 \\
\hline Personal & 21 & 10 & 48 & 11 & 52 \\
\hline Proyección Social & 10 & 2 & 20 & 8 & 80 \\
\hline TOTAL & 110 & 47 & N.A. & 63 & N.A. \\
\hline
\end{tabular}

Fuente: Aplicación de un instrumento de convalidación, Directores y Directoras de la Dirección Regional de Puntarenas, Noviembre 2008.

*(No aplica) 
En el cuadro anterior, se hace un resumen de los indicadores de cada una de las áreas del instrumento aplicado al personal directivo. De ciento diez indicadores, cuarenta y siete de ellos fueron aprobados por las personas encuestadas, destacando las áreas de planificación, usuarios y personal como las que incluyeron la mayoría de los indicadores que se habían propuesto inicialmente.

Además, las áreas de competitividad (resultados del centro que se obtengan en el área educativa o social que contribuya al éxito del mismo), órganos de apoyo, (recursos que posee el centro educativo en beneficio de la organización) procesos (actividades que se desarrollan para lograr la formación del alumno y la prestación de servicios que ofrece el centro educativo) y proyección social (integración de procesos que alcance los resultados deseados de centro, que impacten contundentemente el sistema en que se encuentra inmersa la organización), aportaron pocos ítems para la conformación de la propuesta final.

Los indicadores citados anteriormente, muestran los índices más bajos en la distribución porcentual de la propuesta de autoevaluación para el grupo directivo, como bien lo muestra el gráfico 1 . No obstante, en la administración de la educación se deben tomar en cuenta las áreas antes mencionadas, ya que cada una de ellas es estratégica en las diferentes dimensiones en las que se desarrolla la organización educativa, donde quien administra la institución opera en un ambiente contextual, político y gubernamental, que responde a la consecución de los objetivos, fines y metas de la educación costarricense.

\section{Gráfico 1}

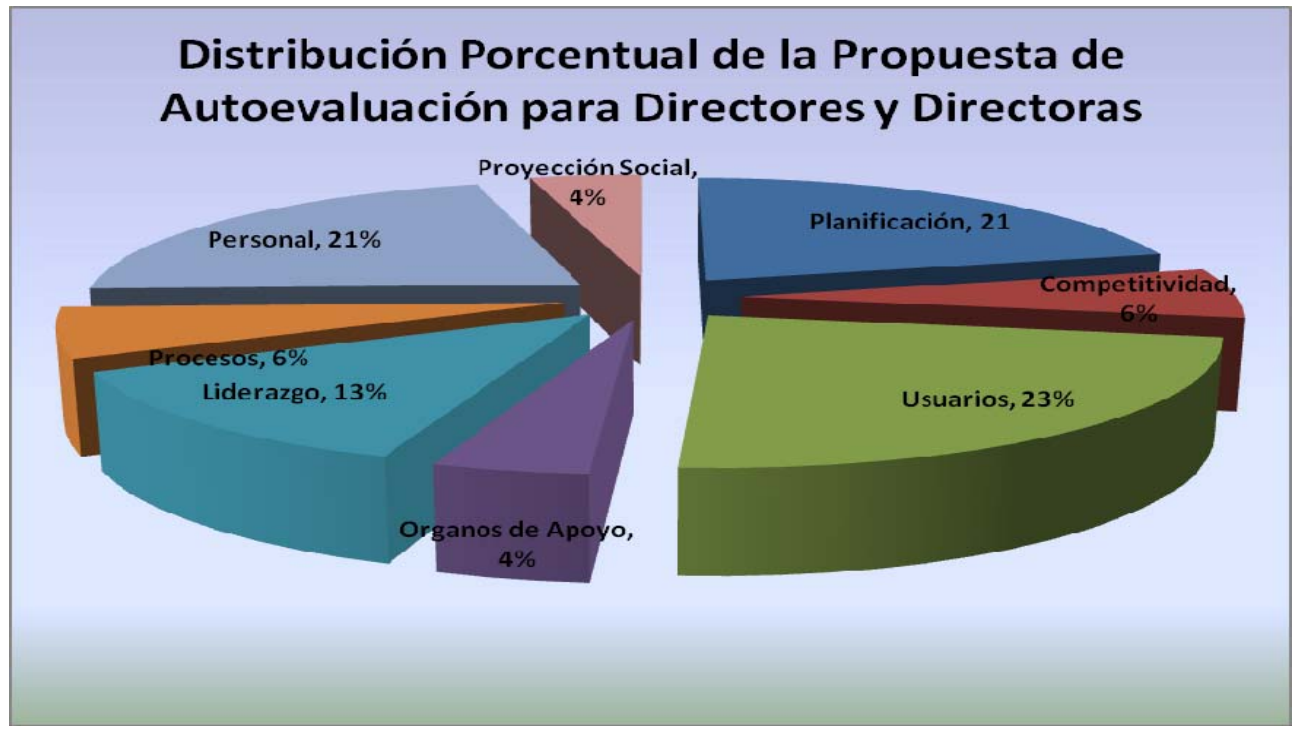

El gráfico 1, también muestra el valor porcentual absoluto de todas las áreas que contempló la propuesta final; de esta manera, el área que más aportó corresponde a usuarios (son usuarios directos el alumno y su familia) con un $23 \%$, seguida de la planificación y personal (forma en que el recurso humano, interno y externo, es guiado 
para lograr la eficiencia y eficacia, en la consecución de los objetivos), con un 21\% cada una. Los gestores consideraron que con la autoevaluación de estas áreas se podría determinar con mayor fidelidad la calidad del servicio educativo que se brindanda. Igualmente, Robbins (2004) determina que la administración de la calidad corresponde al mejoramiento de los procesos, mediante la participación de las personas que trabajan en ello.

En lo que respecta a las áreas que excluyeron elementos destacan las de usuarios, personal y proyección social, las cuales alcanzaron escasamente a incluir siete indicadores en su sumatoria, reflejando porcentajes muy bajos en la propuesta de autoevaluación, que se reflejan en el gráfico 2, donde se resumen las apreciaciones del personal docente sobre los indicadores que seleccionaron; sin embargo, un administrador o administradora de la educación con visión, debe emprender alianzas estratégicas con la comunidad con el propósito de compenetrarse con ella. Igualmente, debe establecer redes de apoyo con los líderes comunales para constituir un equilibrio entre los objetivos organizaciones y comunitarios.

\section{Gráfico 2}

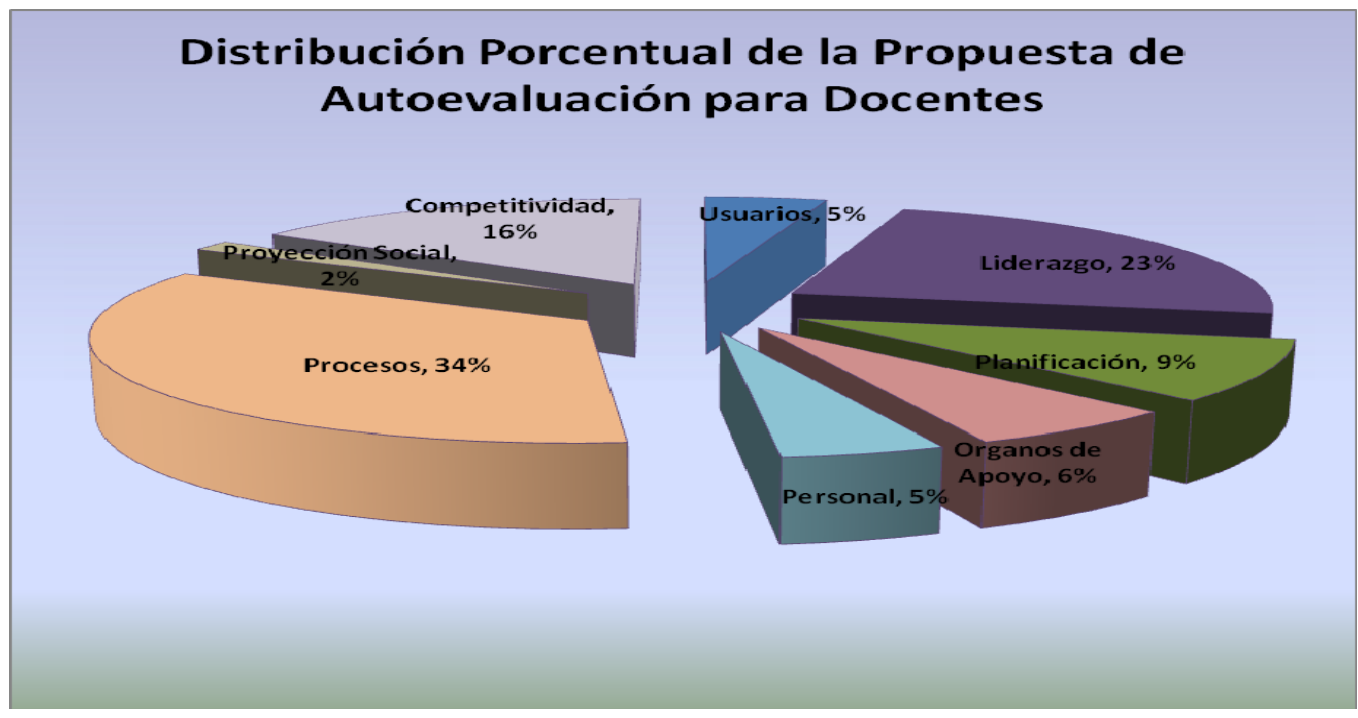

Con base en la información del gráfico 2, llama la atención que exista una diferencia importante entre los indicadores de las áreas de procesos con la de usuarios, puesto que en la práctica pedagógica se encuentran estrechamente relacionados, tanto así que sin la existencia de usuarios no podría darse el proceso educativo. Al respecto, el reto de la administración de la educación es posibilitar que el potencial del ser humano se desarrolle integralmente para la completa realización de las personas, de forma que ello se refleje en su esmero por alcanzar el desarrollo integral de la sociedad.

Para la administración de la educación es primordial el bienestar integral del discente, por lo que no se debe descuidar la satisfacción que sienta el alumnado con el personal docente, para alcanzar los objetivos del proceso de enseñanza y 
aprendizaje, constituyendo un vínculo afectivo que garantice un ambiente propicio para adquirir con gusto y flexibilidad lo que se debe aprender en el salón de clase. Por ende, en los procesos de autoevaluación no se pueden obviar los criterios de esa población $y$, por este motivo, el siguiente gráfico resume sus opiniones sobre la autoevaluación.

\section{Gráfico 3}

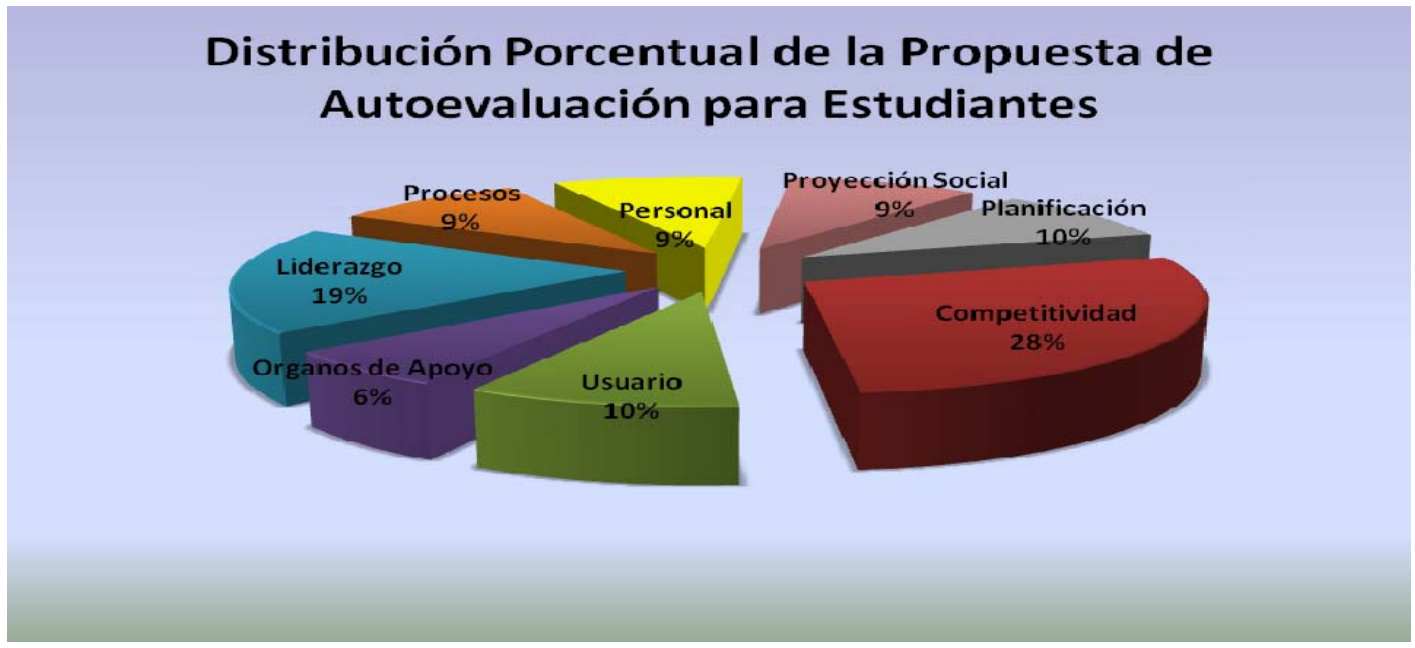

Al observar el gráfico, se determina que la propuesta de autoevaluación se constituye en su mayoría por los criterios de competitividad, seguido por el de liderazgo. Para la administración de la educación una de las áreas más importantes es la gestión del personal. Las personas constituyen el motor de desarrollo de potencialidades y de la creatividad dentro de la organización educativa, constituyéndose en el capital más valioso, puesto que con la innovación es posible el crecimiento y la mejora continua; en consecuencia, el logro de la calidad.

La planificación estratégica en educación consiste en integrar de manera participativa a todos los miembros de la comunidad educativa, con el objetivo de visualizar de varias maneras una misma situación, mediante la reflexión profunda de quienes lo viven, y así tomar la decisión más racional y de consenso, que permita a la organización tener las herramientas necesarias para mantener la competitividad que exige el mundo actual; tal es el caso de los padres y las madres de familia, que se describe en el siguiente gráfico.

\section{Gráfico No 4}




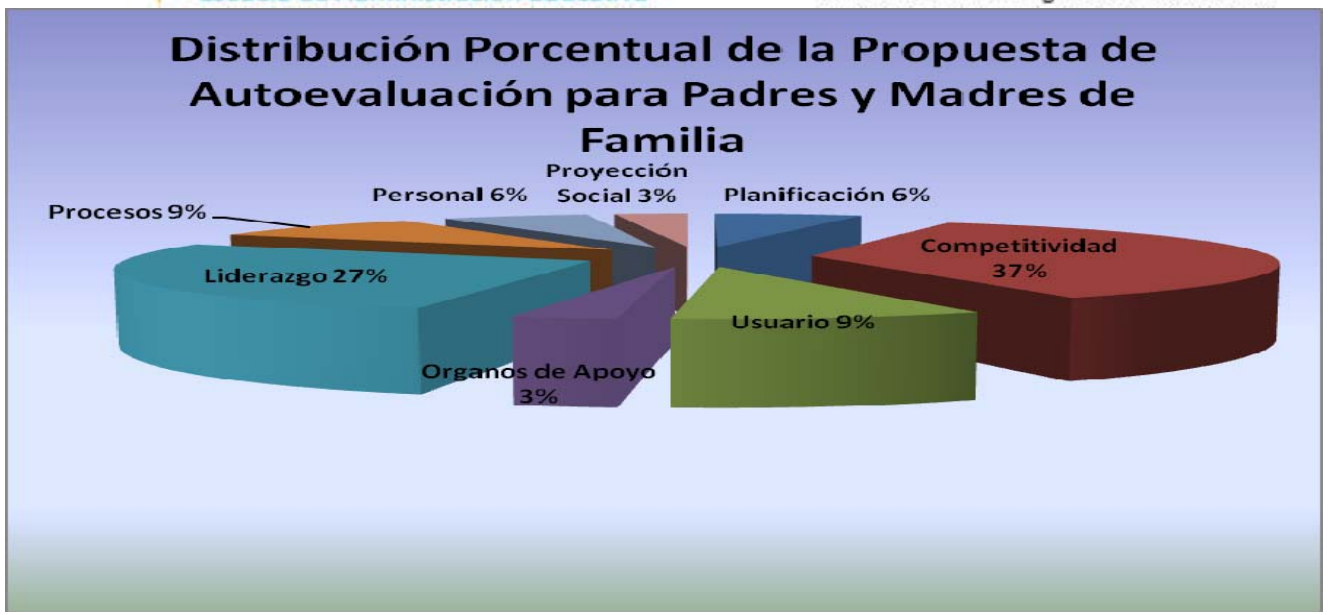

De una manera más amplia, los padres y las madres de familia, si bien necesitan ser atendidos en sus propias necesidades, no se consideran un grupo participativo y útil dentro de la organización; de ahí la importancia de que la administración de la educación se preocupe por darles las herramientas necesarias para que incrementen su grado de participación en las actividades del centro educativo y el proceso de aprendizaje de sus hijos e hijas.

\section{Conclusiones}

Con base en los hallazgos del estudio, se desglosan a continuación las conclusiones más importantes:

1. La aplicación de certificaciones internacionales ISO y EFQM en distintas latitudes en el ámbito empresarial, hace que la administración de la educación considere apropiada su adaptación al ámbito educativo, según experiencias en España, Escocia y México. Por ello, es viable la adaptación de esas normas al contexto socioeducativo de las escuelas dirección uno del circuito 02 de Pitahaya, de la Dirección Regional de Puntarenas.

2. La autoevaluación es un medio idóneo para determinar de una manera participativa la calidad de los procesos educativos, mediante la reflexión sistemática y rigurosa de la evaluación, para la toma de decisiones.

3. La participación de directores, directoras, docentes, estudiantes, madres y padres de familia, en la selección de indicadores de la autoevaluación aplicables a su contexto, valida su efectividad, puesto que parte de las necesidades e intereses de la comunidad educativa, son los criterios establecidos en los estándares de calidad internacional planteados en los modelos ISO y EFQM.

4. El liderazgo fue el área que aportó más indicadores para la propuesta de autoevaluación, de acuerdo con las personas que participaron en el estudio; desde el punto de vista de la administración de la educación 
constituye una de las áreas fundamentales para la gestión de los centros.

5. Otra de las áreas donde la población objeto de estudio determinó gran cantidad de criterios para ser tomados en consideración para la propuesta de autoevaluación fue la planificación. La administración de la educación se caracteriza por ser dinámica, permitiendo reajustar los medios, las actividades, fines métodos y procedimientos de manera concreta, para influir vigorosamente en la realidad que se busca transformar.

6. El área de personal aportó el tercer lugar en orden de relevancia, según los sujetos involucrados en esta investigación, aspecto que determinó la trascendencia de seleccionar criterios concernientes a la forma cómo se gestiona y desarrolla la administración de la educación el potencial de las personas, su conocimiento, experiencia, disponibilidad, e identificación con el centro escolar en el cual se desempeña laboralmente.

7. El área de usuarios determinó un aporte de $49 \%$ de ítems escogidos, para la formulación de la propuesta final de autoevaluación, lo cual evidencia que la administración de la educación tiene un papel protagónico en lo referente a la satisfacción de las necesidades de las poblaciones que atiende e involucra, puesto que ellas son el principal insumo: el alumnado y sus familias, razón de ser de la organización.

8. El área de procesos se acercó a un porcentaje del $50 \%$ de los indicadores escogidos, estableciendo la necesidad de incorporar servicios, estrategias, tareas y procedimientos que ofrece el centro escolar, para alcanzar los objetivos de la organización educativa.

9. El área de competitividad no fue considerada tan necesaria en la inclusión de indicadores para la propuesta de autoevaluación; es decir, las personas consultadas no visualizan ni perciben el grado de cumplimiento de metas y objetivos alcanzados por las organizaciones como lo más relevante.

10. El área de proyección social no fue significativa para los sujetos en estudio, ya que ese indicador resultó con el porcentaje más bajo en todos los instrumentos aplicados.

\section{Propuesta de Autoevaluación para las Escuelas Dirección Uno del Circuito 02, de la Dirección Regional de Puntarenas}

\subsection{Justificación}

La carencia de modelos de autoevaluación en las organizaciones educativas del contexto nacional, orientadas a las escuelas dirección uno, hace ineludible la búsqueda de un modelo de autoevaluación que se ajuste a sus características, necesidades e intereses, así como a las demandas del medio ambiente en el que están circunscritas. Por esta razón, es importante retomar las normas internacionales de calidad, referentes a la autoevaluación de la educación, y la experiencia de países donde se han realizado estudios de las certificaciones internacionales, como España, 
Escocia y México, en la adaptación de modelos como la norma ISO (Organización Internacional para la Estandarización) y la EFQM (Fundación Europea para la Gestión de la Calidad).

Con el fin de garantizar un proceso de autoevaluación basado en la calidad, se adaptaron os modelos mencionados a las escuelas Dirección 1, del Circuito 02 de Pitahaya. Para ello, los indicadores en que se basan se fusionaron en ocho grandes áreas: usuarios, liderazgo, planificación, órganos de apoyo, personal, procesos, proyección social y competitividad. Posteriormente, mediante cuatro cuestionarios dirigidos a directores y directoras, docentes, estudiantes, padres y madres de familia, se procedió a que, de acuerdo con su realidad, las personas indagadas seleccionaran los criterios que consideraran indispensables para autoevaluar los centros educativos en estudio.

La propuesta tuvo los siguientes objetivos los siguientes:

\section{General}

1. Proporcionar al personal directivo de los centros educativos del Circuito 02 de la Dirección Regional de Puntarenas, un instrumento basado en los estándares internacionales de la calidad, para llevar a cabo procesos de autoevaluación institucional.

\section{Específicos}

1. Desarrollar un modelo de autoevaluación para las instituciones Dirección 1, que responda a necesidades e intereses de directoras, directores, docentes, estudiantes, padres y madres de familia.

2. Proponer instrumentos de autoevaluación que permitan obtener resultados de todos los procesos que tienen lugar en un centro educativo, para facilitar ajustes pertinentes a la consecución de las metas, fines y objetivos de las organizaciones educativas.

\subsection{Metodología}

El desarrollo de esta propuesta de autoevaluación consiste en analizar la participación y percepción de los integrantes de la comunidad educativa, compuesta por: directores y directoras, docentes, estudiantes, padres y madres de familia, que indican el estado real de los procesos que se desarrollan en el centro educativo, con el fin de obtener información fidedigna que permita realizar los ajustes necesarios para resolver las inconsistencias y a la vez mantener los procesos que se están ejecutando de una manera adecuada. Dadas las características particulares de las escuelas Dirección 1, para la aplicación de esta propuesta de autoevaluación se considera oportuno emplear los instrumentos de la siguiente manera: 
a. En el caso del director o directora a cargo de la organización educativa, es pertinente aplicarlo a la totalidad de la población.

b. En el caso del personal docente, se debe aplicar a la totalidad de la población.

c. En cuanto al estudiantado, se debe pasar el instrumento a los presidentes y presidentas de las directivas de sección de cada uno de los grados, así como el gobierno estudiantil, puesto que estas personas tienen desarrolladas más destrezas y habilidades sociales que facilitan un conocimiento del entorno educativo; de esta manera, pueden dar aportes significativos al proceso de autoevaluación.

d. Para padres y madres de familia, se pasará el instrumento a aquellos que sean miembros de la junta de educación y del patronato escolar, en razón de que quienes integran esos órganos de apoyo tienen un conocimiento amplio del panorama educativo en el cual se desenvuelven las organizaciones educativas y de esta manera pueden realizar aportaciones interesantes, mediante la autoevaluación, que conduzcan a un crecimiento constante y reflexivo de los diferentes proyectos que tienen lugar en una escuela dirección uno.

\subsection{Instrumentos}

Para hacer realidad el proceso de autoevaluación, se deben aplicar los siguientes instrumentos de autoevaluación, que son producto de la adaptación realizada por los directores directoras, docentes, estudiantes, padres y madres de familia de las escuelas dirección uno del Circuito 02, Pitahaya de la Dirección Regional de Puntarenas, a partir de los modelos internacionales para la estandarización de la calidad de la educación, que aparecerán en el siguiente orden:

- Director o Directora: instrumento que consta de 47 ítems de autoevaluación, constituido por aspectos que los describen, agrupados en ocho áreas claves, que suministran una visión general del resultado de la escuela.

- Docentes: instrumento que consta de 64 ítems, distribuidos en ocho áreas que proporcionan una visión general del resultado de la institución.

- Estudiantes: instrumento con una escala Likert, que consta de 32 ítems de autoevaluación ordenados en ocho áreas clave, que facilitan una visión general del resultado de la organización.

- Padres y madres de familia: consta de 32 ítems de autoevaluación y está constituido por un conjunto de aspectos que los describen, agrupados en ocho áreas, las cuales suministrarán una perspectiva del estado de la escuela. 


\section{\% Gestión

9.4. Metodología para la ejecución del proyecto

Para ejecutar el proceso de autoevaluación, se realizarán los siguientes pasos:

1. Aplicación de los instrumentos: La aplicación de los instrumentos se realiza durante un mes, convocando semanalmente a cada grupo en investigación.

Docentes: Se aplica en la primera semana del mes; para ello, se convocan en una tarde y se facilita el instrumento para que se lo auto apliquen.

Estudiantes: En la segunda semana, se convoca a quienes integran el Gobierno Estudiantil, así como a los presidentes y presidentas de cada sección, a quienes se les brindará el instrumento para que evalúen la institución con la orientación del director o directora.

Padres y Madres de Familia: Esta población será convocada en la tercera semana del mes o aprovechando las reuniones ordinarias del Patronato Escolar y de la Junta de Educación, sus miembros evaluarán el centro escolar.

Director o Directora: Evaluará el centro educativo en la cuarta semana del mes.

2. Tabulación de los resultados: se recomienda el uso de hojas de cálculo de Excel, bajo el nombre de "Captura" de los archivos: "Análisis de la información de Directores.xIsx", "Análisis de la información de Docentes.xIsx", "Análisis de la información de Estudiantes.xIsx" y "Análisis de la información de Padres y Madres de Familia.xlsx", según población. La persona que tabule los cuestionarios únicamente introduce numerales de 1 a 5 , correspondientes a las opciones marcadas en la hoja de cálculo. La sección amarilla es para identificar el folio, los numerales grandes en casilla amarilla, representarán cada indicador.

3. Sistematización de los resultados por medio de cuadros y gráficos estadísticos: Los archivos mencionados se sistematizan en una tercera hoja con cuadros de frecuencias y el porcentaje de las respuestas que se introdujeron en la hoja "Captura". Estos cuadros se actualizan automáticamente y están protegidos para no variar las fórmulas.

En la columna B se muestran los indicadores, seguidos de la media que se obtiene de las respuestas, las frecuencias en que cada opción fue elegida y su respectivo porcentaje, el área presenta los promedios obtenidos y serán utilizados para graficar los resultados por áreas.

Interpretación de los resultados: Cada respuesta tiene un color definido: Nunca, rojo; La mayoría de las veces no, amarilla; Algunas veces sí, algunas veces no, verde; La mayoría de las veces sí, celeste, y Siempre, gris. Dando un matiz de alerta, para que el evaluador tome conciencia del desempeño de calidad que está ofreciendo en ese indicador. Por ello, en la hoja "Análisis", cada indicador se grafica al lado, para que sea perceptible a simple vista. Los gráficos se actualizan y se basan en los porcentajes de la hoja "Tabulación". 
El proceso explicado, se efectúa para cada población y de esta manera se obtienen los resultados de la autoevaluación de cada área por población, donde se se generan ocho gráficos, uno para cada área.

Para obtener una autoevaluación integral donde se relacionen las opiniones del Director o Directora, Docentes, Estudiantes y Padres y madres de Familia, se crea el archivo "Resumen de Autoevaluación Institucional.xlsx". Este archivo muestra la hoja con el cuadro que resume los promedios de cada población por área, luego se grafican automáticamente.

Esta propuesta de autoevaluación es de fácil aplicación, puesto que solo requiere la disposición del personal involucrado, de la obtención de la información, para luego proceder a tabularla mediante los archivos que se generan en Excel.

Para lograr una aplicación correcta del la propuesta de autoevaluación, es preciso leer adecuadamente la metodología, con el propósito de garantizar que los resultados sean fidedignos y reflejen el estado real de la organización educativa.

Esta propuesta de autoevaluación es aplicable a organizaciones educativas tipo Dirección 1 y con ciertos ajustes en las hojas electrónicas puede adaptarse para autoevaluar instituciones con rangos de matrícula más elevados. La autoevaluación institucional puede efectuarse en el momento en que se considere apropiado y los tiempos que se muestran en esta propuesta pueden ser modificados, dependiendo de las necesidades y características de la institución y la comunidad educativa.

\section{Referencias bibliográficas}

Andrés, M. (2005). Propuesta de indicadores del proceso de enseñanza/aprendizaje en la formación profesional en un contexto de gestión de calidad total. Revista ELectrónica de Investigación y Evaluación Educativa. Recuperado el 11 de abril, 2008 de: http://www.uv.es/RELIEVE/v10n2/RELIEVEv11n1 4.htm

Blanco, R. (2004). Conferencias Magistrales del Ministerio de Educación. Fundación Mundo de Oportunidades. San José, Costa Rica: EDITORAMA.

Bisquerra, R. (2000). Métodos de Investigación Educativa: Guía Práctica. Barcelona. España: Ceac.

Carrión, A. (2006). El Modelo EFQM Más allá del ISO 9000. Revista de la Información Básica. Recuperado el 2 de abril, 2008 de: http://www.dane.gov.co/revista ib/html r1/articulo12 r1.htm

Chaves, R. (2005). ISO 9000 y El control de los Documentos. Recuperado el 19 de diciembre, 2008

de: www.una.ac.cr/bibliotrcología/boletínbiblioteca/2005/Rosario.doc 
Chiavenato, I. (2007). Administración de Recursos Humanos. México D.F.: McGrawHill.

Chiavenato, I. (2007). Introducción a la Teoría General de la Administración. México D.F.: McGraw-Hill.

De Miguel, F. (1997). La evaluación de los centros educativos. Una aproximación a un enfoque sistémico. Revista de Investigación Educativa, 15 (2), 145-178.

Dirección General de Políticas de México. (2006). Autoevaluación de Centros Escolares. Dirección de Evaluación de Programas y Estudios Especiales. Recuperado el 10 de abril, 2008 de: http://www.comipems.org.mx/autoevaluacion/ACEMMCT.php\#Caracteristicas

Dorado, A. y Gallardo, L. (2005). La Gestión del Deporte a Través de la Calidad. Barcelona: INDE.

Doris, J. (2002). Las ISO 9000 para las PyMES. Recuperado el 15 de diciembre, 2008 de: www.canacyt.gob.su/LasISO9000PyMESRevESCyT-07-10-2002.doc

Escudero, T. (2007). Claves identificativas de la investigación evaluativa. Contextos Educativos. 8-9: 179-199. Recuperado el 17 de abril, 2008 de: http://www.unirioja.es/servicios/sp/ej/contextos/infos/2091397.pdf

Escudero, T. (1997). Enfoques modélicos y estrategias en la evaluación de centros educativos. RELIEVE, 3(1). Recuperado el 12 de setiembre, 2008 de: http://www.uv.es/RELIEVE/v3n1/RELIEVEv3n1 1.htm

Gairín, J. (2002). La evaluación de centros educativos, en Castillo Arredondo, S. Compromisos de la Evaluación Educativa. Madrid: Prentice Hall.

Garbanzo, G. y Orozco, V. (2007). Desafíos del sistema educativo costarricense: un nuevo paradigma de la administración de la educación. Revista de Educación, 31 (2), 95-110.

García, B. (2005). La cultura de la evaluación como proceso de mejora de un centro educativo: Informe final de graduación para optar por el grado de Doctorado en Educación. Granada, España: Editorial de la Universidad de Granada.

Gento, S. (2000). Gestión y supervisión de Centros Educativos. San José. Costa Rica: Editorial EUNED.

Guadamuz, L. (1980). La administración educativa y su relación con la administración pública. San José, Costa Rica: EUNED.

Jimenez, W. (2003). Evolución del Pensamiento Administrativo en la Educación Costarricense. San José, Costa Rica: EUNED. 
Lafourcade, P. (2005). Evaluación institucional. San José, Costa Rica: EUNED.

Luján, J y Puente, J. (1996). Evaluación de centros docentes PLAN EVA. Madrid: Centro de publicaciones de la Secretaría General Técnica.

Lukas, J. (2004, Marzo). Evaluación de centros escolares de educación secundaria del País Vasco. Revista Electrónica de Investigación Educativa. Recuperado el 11 de abril, 2008 de: http://redie.uabc.mx/vol6no2/contenido-lukas.html

Ministerio de Educación, Cultura y Deporte. (2001). Modelo Europeo de Excelencia. Secretaría de Estado de Educación, Madrid, España. Recuperado el 03 de noviembre, 2008 de: http://www.mepsyd.es/educa/calidad/files/modelo.pdf

Ministerio de Educación y Cultura. (1999). Evaluación en escuelas de Europa. Secretaría de Estado de Educación, Madrid, España. Recuperado el 14 de abril, 2008 de: http://presencias.net/indpdm.html?http://presencias.net/educar/ht1048a.html

Ministerio de Planificación Nacional y Política Económica. (2008). Segundo Taller Organizado de MIDEPLAN. San José, Costa Rica. Recuperado el 16 de junio, 2008 de: http://www.mideplan.go.cr/

Organización de Estados Iberoamericanos. (2007). Noticias: Uruguay-PISA 2007. Recuperado el 21 de abril, 2008 de: http://www.oei.es/noticias/spip.php?article1578\&debut 5ultimasOEI=40

Pallán, C. (1978). Bases para la Administración de la Educación Superior en América Latina: el caso de México. México D.F.: Ediciones Instituto Nacional de Administración Pública.

Paniagua, C. (2005). Principales escuelas del pensamiento administrativo. San José, Costa Rica: EUNED.

Pereira, M ${ }^{a}$ T. (1993). Orientación del estudiante de enseñanza Primaria. San José, Costa Rica: EUNED.

Pérez, Z. (2006) Un enfoque sobre le gestión del conocimiento desde la perspectiva de la calidad. Recuperado 04 de noviembre, 2008 de: http://secretosenred.com/articles/2129/Un-Enfoque-sobre-La-Gestión- delconocimiento-desde-la-perspectiva-de-la-calidad/pagel.html

Rey, R. y Santamaría J. (2000). Trasformar la educación en un contrato de calidad. Barcelona: Editorial CISS PRAXIS.

Riggs, F. (1993). Teoría, integración y formalismo. México D.F.: Limusa Wiley. 
Robbins, S. (2004). Comportamiento organizacional. México: Pearson Educación.

Romero, F. (2001). Supervisión y evaluación de centros educativos. San José. Costa Rica: Editorial Universidad de Costa Rica.

Ruiz, J. (1999). Cómo hacer una evaluación de centros educativos. Madrid. España: Editorial Narcea.

Sander, B. (1990) Educación Administración y calidad de vida. España: Editorial Santillana.

Sander, B. (s.f.) Nuevas tendencias en la gestión educativa: democracia y calidad. Recuperado de http://www.iacd.Oas.org/La\%20Educa\%20123-125/sand.htm

Santos, M. (1996). Evaluación educativa 2: Un enfoque práctico de la evaluación de alumnos, profesores, centros educativos y materiales didácticos. Buenos Aires: Editorial Magisterio del Río de la Plata.

Santos, M. (2000). Evaluación educativa1: un proceso de diálogo comprensión y mejora. Buenos Aires: Editorial Magisterio del Río de la Plata.

Tiana, A. (1996) La evaluación de los sistemas educativos. Revista Iberoamericana de Educación. No. 10. Recuperado el 15 de abril, 2008 de: http://www.oei.es/oeivirt/rie10a02.htm

Valeirón, J. (1996). Modelo de gestión de la calidad para los centros educativos. República Dominicana: Ed. Educativa.

Venegas, P. (2006). Planificación educativa: Bases metodológicas para su desarrollo en el siglo XXI. San José, Costa Rica: EUNED.

Villalobos, J. (2006). Educar en tecnologías de Información. Revista de Derecho y Tecnología de la información No. 4-2006. UNED, Costa Rica. Recuperado el 23 de noviembre, 2007 de: http://www.uned.ac.cr/Redti/cuarta/art1.pdf

Villalta, A. (2007). Propuesta del Manual del Sistema de Gestión de la Calidad (SGC) en la Universidad Tecnológica de El Salvador. San Salvador, El Salvador: Editorial Universidad Tecnológica de El Salvador.

Zúñiga, H. (2003). La Autoevaluación en una Escuela Dirección 2 Plan de Mejoramiento. Informe final para optar por el grado académico de Maestría en Administración Educativa, Sede Universitaria Rodrigo Facio. 